Supporting Information for

\title{
Auger-Assisted Electron Transfer between Adjacent Quantum Wells in Two-Dimensional Layered Perovskites
}

\author{
Zixi Yin, ${ }^{+}$Jing Leng, ${ }^{*}+$ Shiping Wang, ${ }^{+,+}$Guijie Liang, ${ }^{\S}$ Wenming Tian, ${ }^{*}+$ Kaifeng $W u^{\dagger}$ and \\ Shengye $\mathrm{Jin}^{*},+$
}

${ }^{\dagger}$ State Key Laboratory of Molecular Reaction Dynamics and Dynamics Research Center for Energy and Environmental Materials, Dalian Institute of Chemical Physics, Chinese Academy of Sciences, Dalian 116023, China

University of Chinese Academy of Sciences, Beijing 100049, China

\$Hubei Key Laboratory of Low Dimensional Optoelectronic Materials and Devices, Hubei University of Arts and Science, Xiangyang, Hubei, 441053, China

\section{Sample preparations and experimental setup}

\section{Synthesis of $\left(\mathrm{C}_{8} \mathrm{H}_{17} \mathrm{NH}_{3}\right)_{2} \mathrm{PbI}_{4}$ and $\left(\mathrm{C}_{10} \mathrm{H}_{21} \mathrm{NH}_{3}\right)_{2} \mathrm{PbI}_{4}$ single crystals}

$\mathrm{PbI}_{2}$ powder $(0.2305 \mathrm{~g}, 0.25 \mathrm{mmol}), \mathrm{C}_{8} \mathrm{H}_{17} \mathrm{NH}_{2}(0.083 \mathrm{ml}, 0.5 \mathrm{mmol})$ were mixed with $57 \% \mathrm{w} / \mathrm{w} \mathrm{HI}(1 \mathrm{ml}), 50 \% \mathrm{H}_{3} \mathrm{PO}_{2}(0.17 \mathrm{ml})$ and $5 \mathrm{ml}$ ethyl acetate, and heated to $70{ }^{\circ} \mathrm{C}$ under constant stirring. The mixture became clear yellow solution after all precursors were dissolved and was kept stirring at $70{ }^{\circ} \mathrm{C}$ for about $2 \mathrm{~h}$. Then the solution was slowly cooled down to room temperature and layered 2D crystals with an orange color were obtained. These crystals were washed by anhydrous ether for four times and then dried at $60{ }^{\circ} \mathrm{C}$ for $24 \mathrm{~h}$ under a vacuum environment. The $\left(\mathrm{C}_{10} \mathrm{H}_{21} \mathrm{NH}_{3}\right)_{2} \mathrm{PbI}_{4}$ single crystals were synthesized by replacing $\mathrm{C}_{8} \mathrm{H}_{17} \mathrm{NH}_{2}$ with $\mathrm{C}_{10} \mathrm{H}_{21} \mathrm{NH}_{2}(0.5 \mathrm{mmol}, 0.1077 \mathrm{ml})$ without changing other conditions.

\section{Synthesis of $\left(\mathrm{C}_{12} \mathrm{H}_{25} \mathrm{NH}_{3}\right)_{2} \mathrm{PbI}_{4}$ and $\left(\mathrm{C}_{18} \mathrm{H}_{37} \mathrm{NH}_{3}\right)_{2} \mathrm{PbI}_{4}$ single crystals}

$\mathrm{PbI}_{2}$ powder $(0.048 \mathrm{~g}), \mathrm{C}_{12} \mathrm{H}_{25} \mathrm{NH}_{2}(0.037 \mathrm{ml}), 57 \% \mathrm{w} / \mathrm{w} \mathrm{HI}(2.47 \mathrm{ml}), 50 \% \mathrm{w} / \mathrm{w}$ $\mathrm{H}_{3} \mathrm{PO}_{2}(0.41 \mathrm{ml}), 3 \mathrm{ml}$ ethyl acetate and $5 \mathrm{ml}$ anhydrous methanol were mixed, and heated to $70{ }^{\circ} \mathrm{C}$ and kept stirring for $2 \mathrm{~h}$. The saturated mixture was cooled down to room temperature to get yellow crystals. These crystals were rinsed by anhydrous ether for purification and dried at $60{ }^{\circ} \mathrm{C}$ for $24 \mathrm{~h}$ under a vacuum environment. For the 
synthesis of $\left(\mathrm{C}_{18} \mathrm{H}_{37} \mathrm{NH}_{3}\right)_{2} \mathrm{PbI}_{4}$ single crystals, the amounts of raw materials were changed to $\mathrm{PbI}_{2}$ powder $(0.033 \mathrm{~g}), \mathrm{C}_{18} \mathrm{H}_{37} \mathrm{NH}_{2}(0.008 \mathrm{~g}), 57 \% \mathrm{w} / \mathrm{w} \mathrm{HI}(0.825 \mathrm{ml})$, $50 \% \mathrm{H}_{3} \mathrm{PO}_{2}(0.137 \mathrm{ml}), 10 \mathrm{ml}$ ethyl acetate, while other conditions remained the same.

\section{Femtosecond and Nanosecond transient absorption measurement}

The femtosecond transient absorption setup used for this study is based on a regenerative amplified Ti:sapphire laser system from Coherent $(800 \mathrm{~nm}, 35 \mathrm{fs}, 6 \mathrm{~mJ}$ pulse $^{-1}$, and $1 \mathrm{kHz}$ repetition rate), nonlinear frequency mixing techniques and the Femto-TA100 spectrometer (Time-Tech Spectra). Briefly, the $800 \mathrm{~nm}$ output pulse from the regenerative amplifier was split in two parts with a $50 \%$ beam splitter. The transmitted part was used to pump a TOPAS Optical Parametric Amplifier (OPA) which generates a wavelength-tunable laser pulse from $250 \mathrm{~nm}$ to $2.5 \mu \mathrm{m}$ as pump beam. The reflected $800 \mathrm{~nm}$ beam was split again into two parts. One part with less than $10 \%$ was attenuated with a neutral density filter and focused into a $2 \mathrm{~mm}$ thick sapphire window to generate a white light continuum (WLC) from $420 \mathrm{~nm}$ to $800 \mathrm{~nm}$ used for probe beam. The probe beam was focused with an Al parabolic reflector onto the sample. After the sample, the probe beam was collimated and then focused into a fiber-coupled spectrometer with CMOS sensors and detected at a frequency of $1 \mathrm{kHz}$. The delay between the pump and probe pulses was controlled by a motorized delay stage. The pump pulses were chopped by a synchronized chopper at $500 \mathrm{~Hz}$ and the absorbance change was calculated with two adjacent probe pulses (pump-blocked and pump-unblocked). All experiments were performed at room temperature.

Nanosecond TA measurement was performed with the EOS spectrometer (Ultrafast Systems LLC). The pump beam is generated in the same way as the femtosecond TA experiment described above. A different white light continuum (380-1700 nm, $0.5 \mathrm{~ns}$ pulse width, $20 \mathrm{kHz}$ repetition rate) was used, which was generated by focusing a Nd:YAG laser into a photonic crystal fiber. The delay time between the pump and probe beam was controlled by a digital delay generator 
(CNT-90, Pendulum Instruments).

UV-vis absorption and PL spectra of 2D layered perovskites and their structure characterization

The UV-vis absorption spectra were recorded by using a UV-vis absorption spectrometer (Cary60, Agilent Technologies, USA). The PL spectra were obtained by a monochromator (SpectraPro-HRS-300, Princeton Instruments, USA) coupled with a charge coupled device (CCD) camera (PIXIS 100, Princeton Instruments, USA). The excitation beam was picosecond pulse diode laser with $405 \mathrm{~nm}$ output wavelength (35 ps pulse width, PIXEA-405, Aurea Technology, France) and was focused on the sample by objective lens $(100 \times, \mathrm{NA}=0.95)$. X-ray diffraction $(\mathrm{XRD})$ patterns were obtained on a X'pert Pro X-Ray Diffractometer (PANAlytical, Netherlands) using $\mathrm{Cu}$ $\mathrm{K} \alpha$ radiation. 


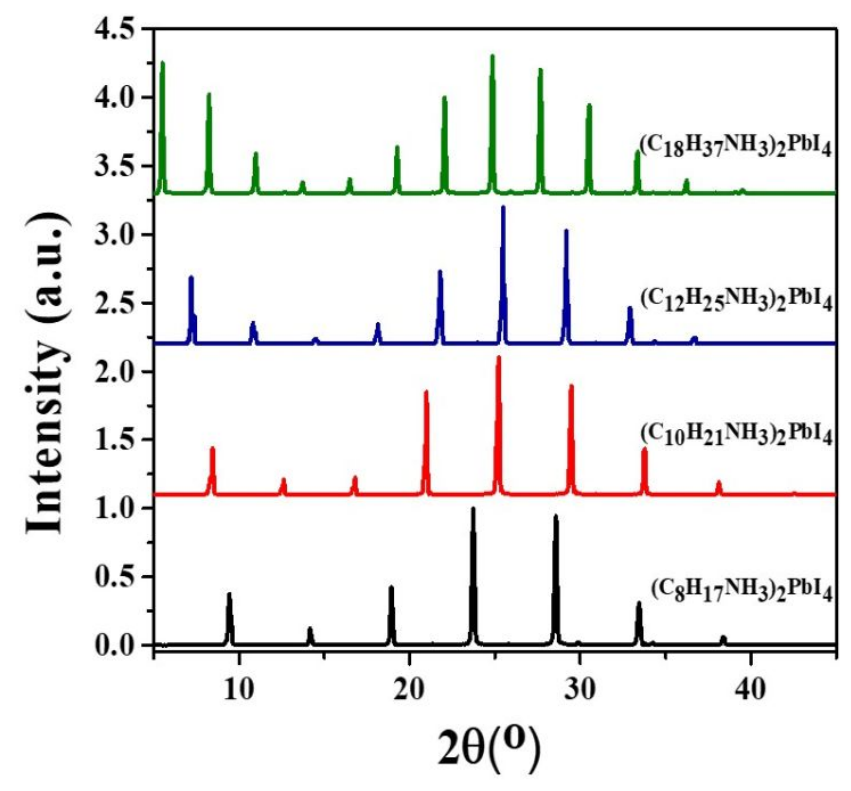

Figure S1. XRD results of $\left(\mathrm{C}_{\mathrm{m}} \mathrm{H}_{2 \mathrm{~m}+1} \mathrm{NH}_{3}\right)_{2} \mathrm{PbI}_{4}(\mathrm{~m}=8,10,12,18)$ single crystals
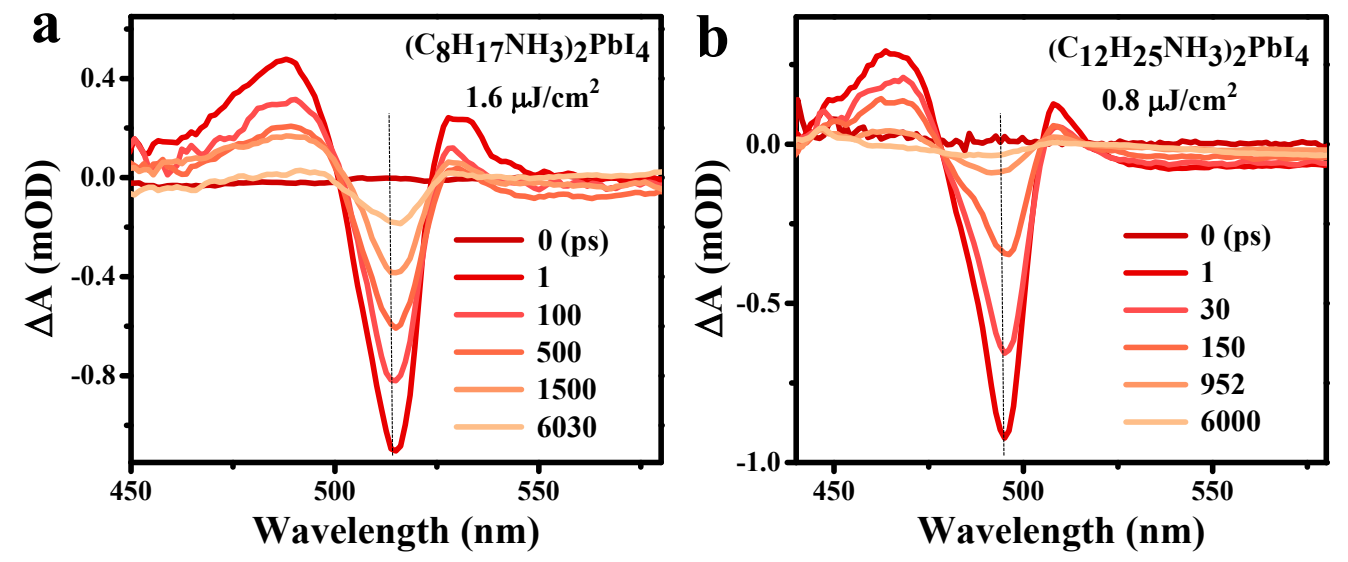

Figure S2. TA spectra of $\left(\mathrm{C}_{\mathrm{m}} \mathrm{H}_{2 \mathrm{~m}+1} \mathrm{NH}_{3}\right)_{2} \mathrm{PbI}_{4}$ 2D perovskites with (a) $\mathrm{m}=8$ and (b) $\mathrm{m}=12$ at the indicated delay times under low-intensity excitation at $400 \mathrm{~nm}$. 

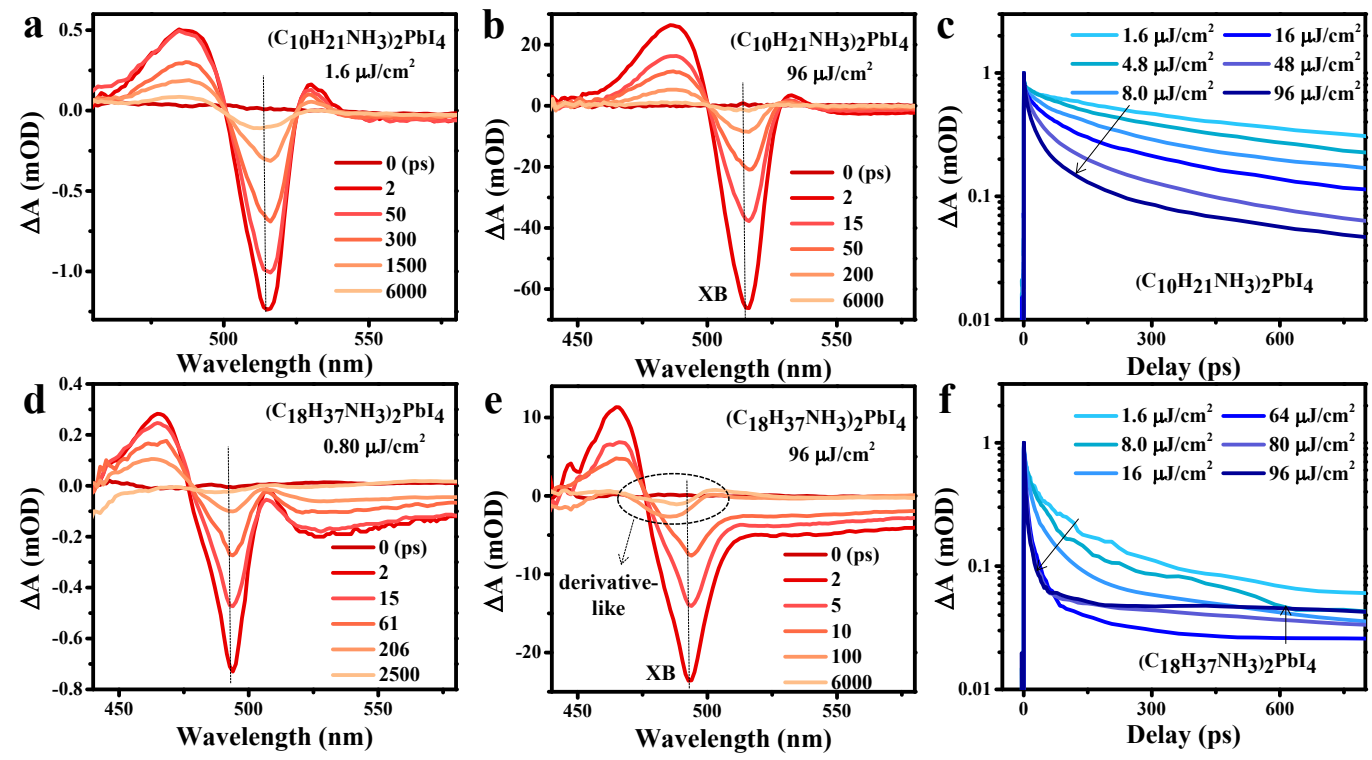

Figure S3. TA spectra of $\left(\mathrm{C}_{10} \mathrm{H}_{21} \mathrm{NH}_{3}\right)_{2} \mathrm{PbI}_{4}(\mathrm{a}, \mathrm{b})$ and $\left(\mathrm{C}_{18} \mathrm{H}_{37} \mathrm{NH}_{3}\right)_{2} \mathrm{PbI}_{4}(\mathrm{~d}, \mathrm{e})$ perovskites recorded at the indicated delay times under $400 \mathrm{~nm}$ excitation with low and high intensities; (c, f) Comparison of XB kinetics of $\left(\mathrm{C}_{10} \mathrm{H}_{21} \mathrm{NH}_{3}\right)_{2} \mathrm{PbI}_{4}$ and $\left(\mathrm{C}_{18} \mathrm{H}_{37} \mathrm{NH}_{3}\right)_{2} \mathrm{PbI}_{4}$ under $400 \mathrm{~nm}$ excitation with different intensities. 

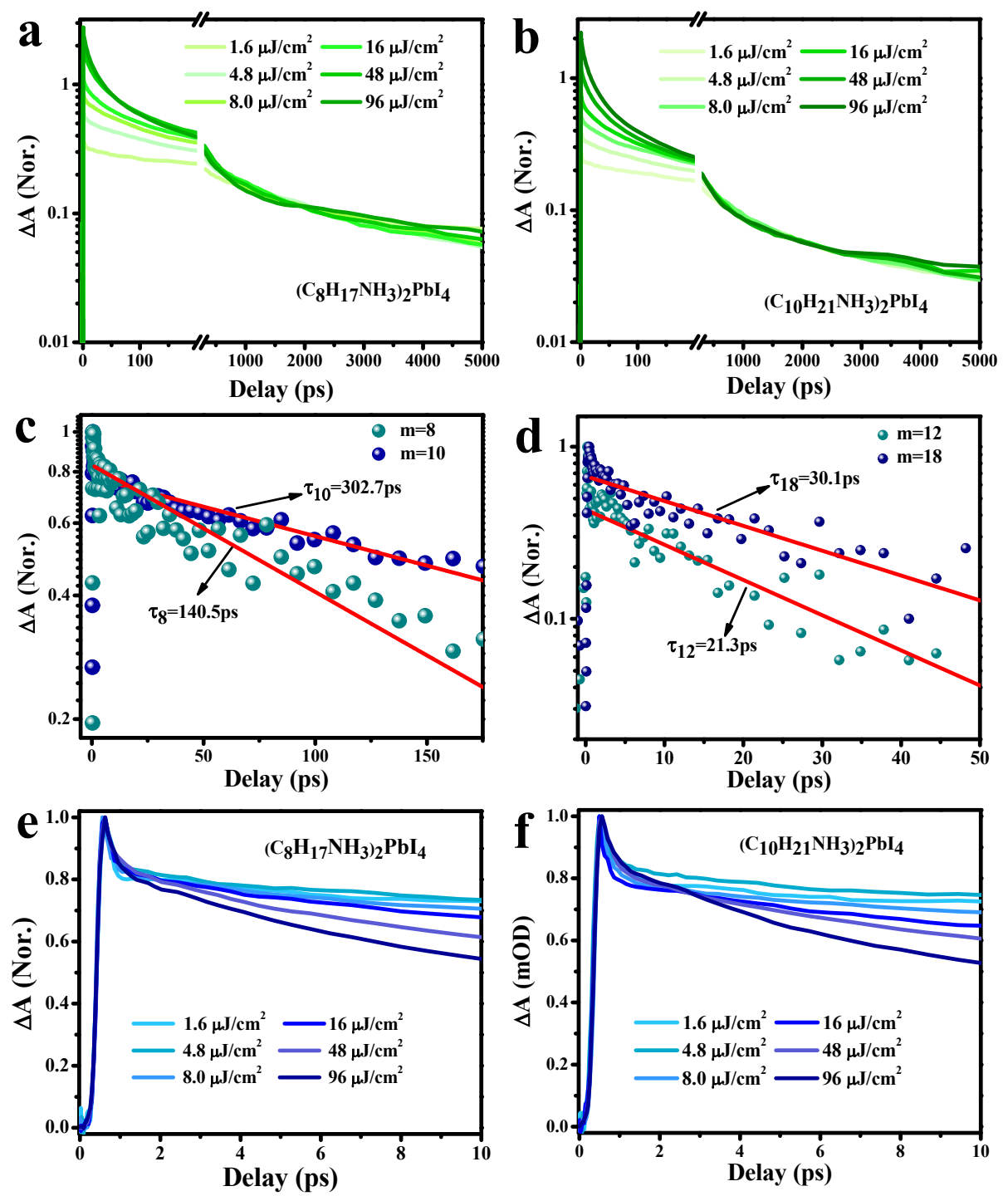

Figure S4. $\mathrm{XB}$ kinetics of (a) $\left(\mathrm{C}_{8} \mathrm{H}_{17} \mathrm{NH}_{3}\right)_{2} \mathrm{PbI}_{4}$ and (b) $\left(\mathrm{C}_{10} \mathrm{H}_{21} \mathrm{NH}_{3}\right)_{2} \mathrm{PbI}_{4} \mathrm{SCs}$ normalized to the long-lived tail under $400 \mathrm{~nm}$ excitation with different intensities, indicating the occurrence of Auger recombination of excitons. (c) Biexciton recombination kinetics for $\left(\mathrm{C}_{8} \mathrm{H}_{17} \mathrm{NH}_{3}\right)_{2} \mathrm{PbI}_{4}$ and $\left(\mathrm{C}_{10} \mathrm{H}_{21} \mathrm{NH}_{3}\right)_{2} \mathrm{PbI}_{4}$ perovskites obtained by subtracting the decay kinetics at excitation intensity of $1.6 \mu \mathrm{J} / \mathrm{cm}^{2}$ from that at excitation intensity of $4.8 \mu \mathrm{J} / \mathrm{cm}^{2}$ (data in panel a and $\mathrm{b}$ ). The red solid lines are fits of data to single-exponential function, determining the Auger recombination times ( $\tau$ ) of 140.5 ps for $\mathrm{m}=8$ and 302.7 ps for $\mathrm{m}=10$ perovskites. (d) Biexciton recombination kinetics for $\left(\mathrm{C}_{12} \mathrm{H}_{25} \mathrm{NH}_{3}\right)_{2} \mathrm{PbI}_{4}$ and $\left(\mathrm{C}_{18} \mathrm{H}_{37} \mathrm{NH}_{3}\right)_{2} \mathrm{PbI}_{4}$ obtained by the same method as for $m=8$ and 10 perovskites. The Auger recombination times are found to be 21.3 ps for $\mathrm{m}=12$ and $30.1 \mathrm{ps}$ for $\mathrm{m}=18$ perovskites. Normalized XB 
kinetics of (e) $\left(\mathrm{C}_{8} \mathrm{H}_{17} \mathrm{NH}_{3}\right)_{2} \mathrm{PbI}_{4}$ and (f) $\left(\mathrm{C}_{10} \mathrm{H}_{21} \mathrm{NH}_{3}\right)_{2} \mathrm{PbI}_{4} \mathrm{SCs}$ in the first 10 ps time window under 400nm excitation with different intensities. The ultrafast decay kinetics within $1.5 \mathrm{ps}$ is the hot electron relaxation, which is much faster than the Auger recombination process.
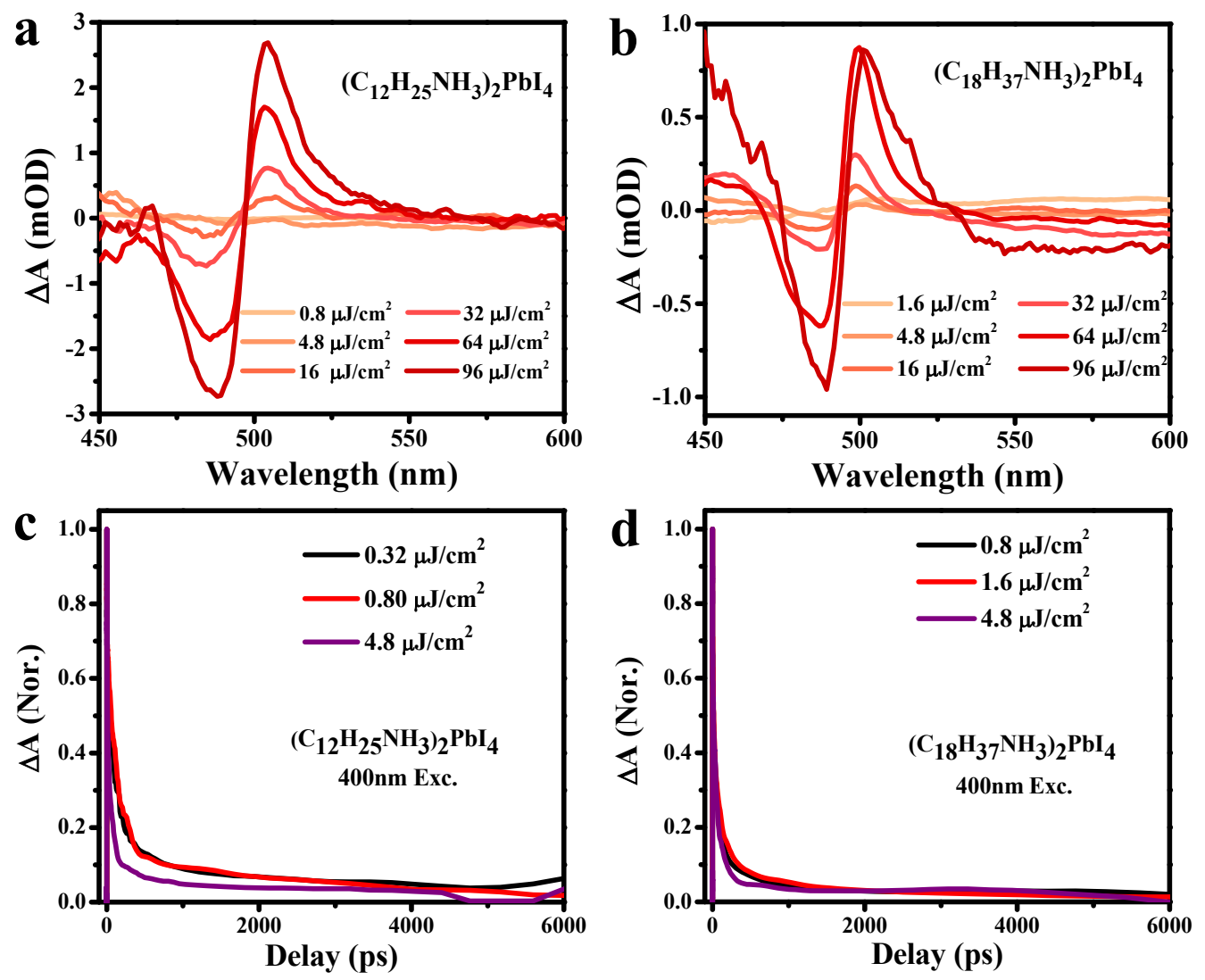

Figure S5. TA spectra of (a) $\left(\mathrm{C}_{12} \mathrm{H}_{25} \mathrm{NH}_{3}\right)_{2} \mathrm{PbI}_{4}$ and (b) $\left(\mathrm{C}_{18} \mathrm{H}_{37} \mathrm{NH}_{3}\right)_{2} \mathrm{PbI}_{4} \mathrm{SCs}$ recorded at a delay time of $6.5 \mathrm{~ns}$ under $400 \mathrm{~nm}$ excitation with different intensities, showing that the derivative-like signal is only observed when the excitation intensity is $\geq 4.8 \mu \mathrm{J} / \mathrm{cm}^{2}$. XB kinetics of (c) $\left(\mathrm{C}_{12} \mathrm{H}_{25} \mathrm{NH}_{3}\right)_{2} \mathrm{PbI}_{4}$ and (d) $\left(\mathrm{C}_{18} \mathrm{H}_{37} \mathrm{NH}_{3}\right)_{2} \mathrm{PbI}_{4} \mathrm{SCs}$ under low excitation intensities, showing that the Auger recombination begins when the excitation intensity is $\geq 4.8 \mu \mathrm{J} / \mathrm{cm}^{2}$. 


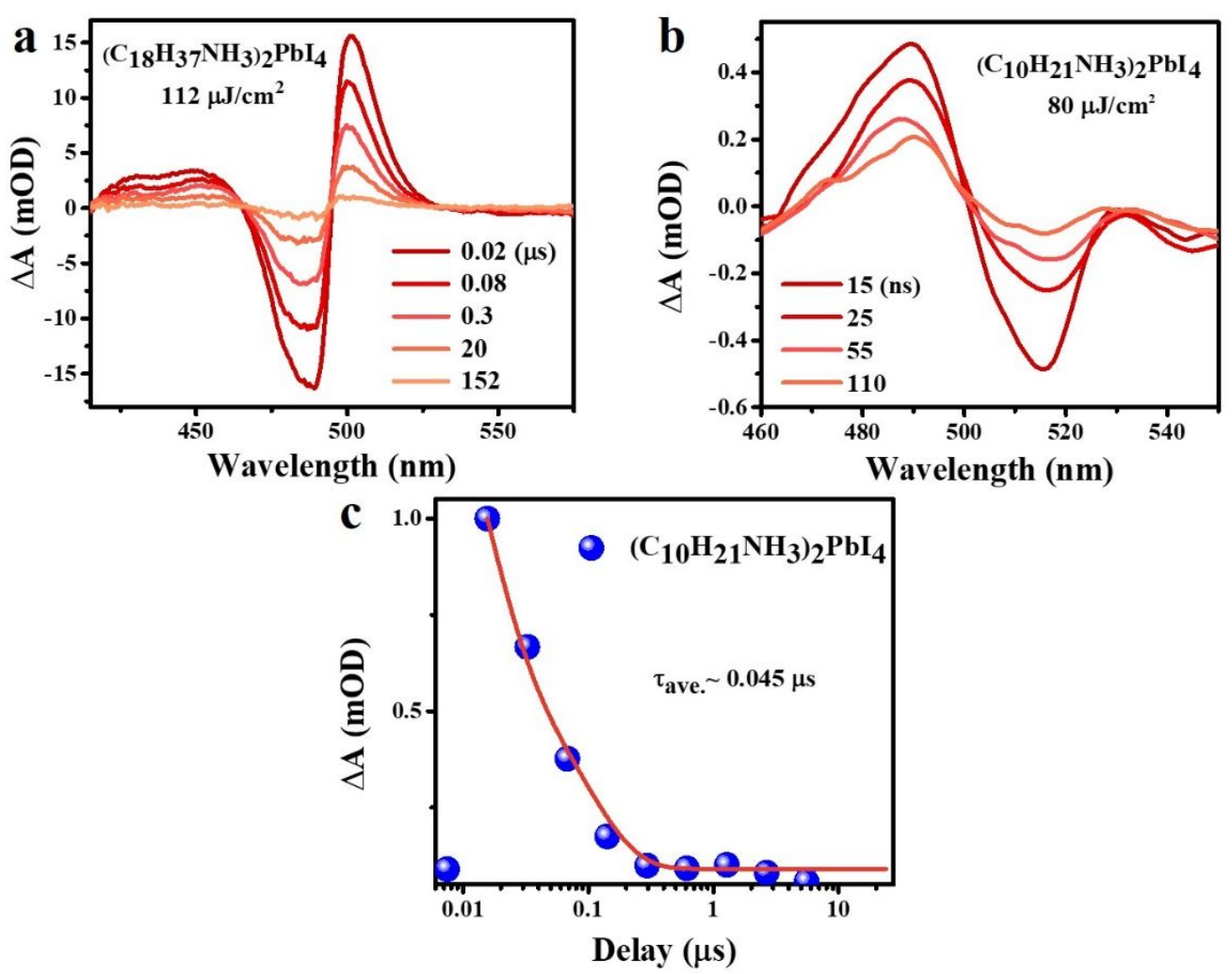

Figure S6. Nanosecond TA spectra of (a) $\left(\mathrm{C}_{18} \mathrm{H}_{37} \mathrm{NH}_{3}\right)_{2} \mathrm{PbI}_{4}$ and (b) $\left(\mathrm{C}_{10} \mathrm{H}_{21} \mathrm{NH}_{3}\right)_{2} \mathrm{PbI}_{4} \mathrm{SCs}$ at indicated delays with $350 \mathrm{~nm}$ excitation under high excitation intensity. (c) Nanosecond XB kinetics of $\left(\mathrm{C}_{10} \mathrm{H}_{21} \mathrm{NH}_{3}\right)_{2} \mathrm{PbI}_{4} \mathrm{SCs}$ under 350 nm excitation. The solid line is the fit of the kinetics with multi-exponential function, yielding an average lifetime of $0.045 \mu$ s for $\mathrm{m}=102 \mathrm{D}$ perovskites. 

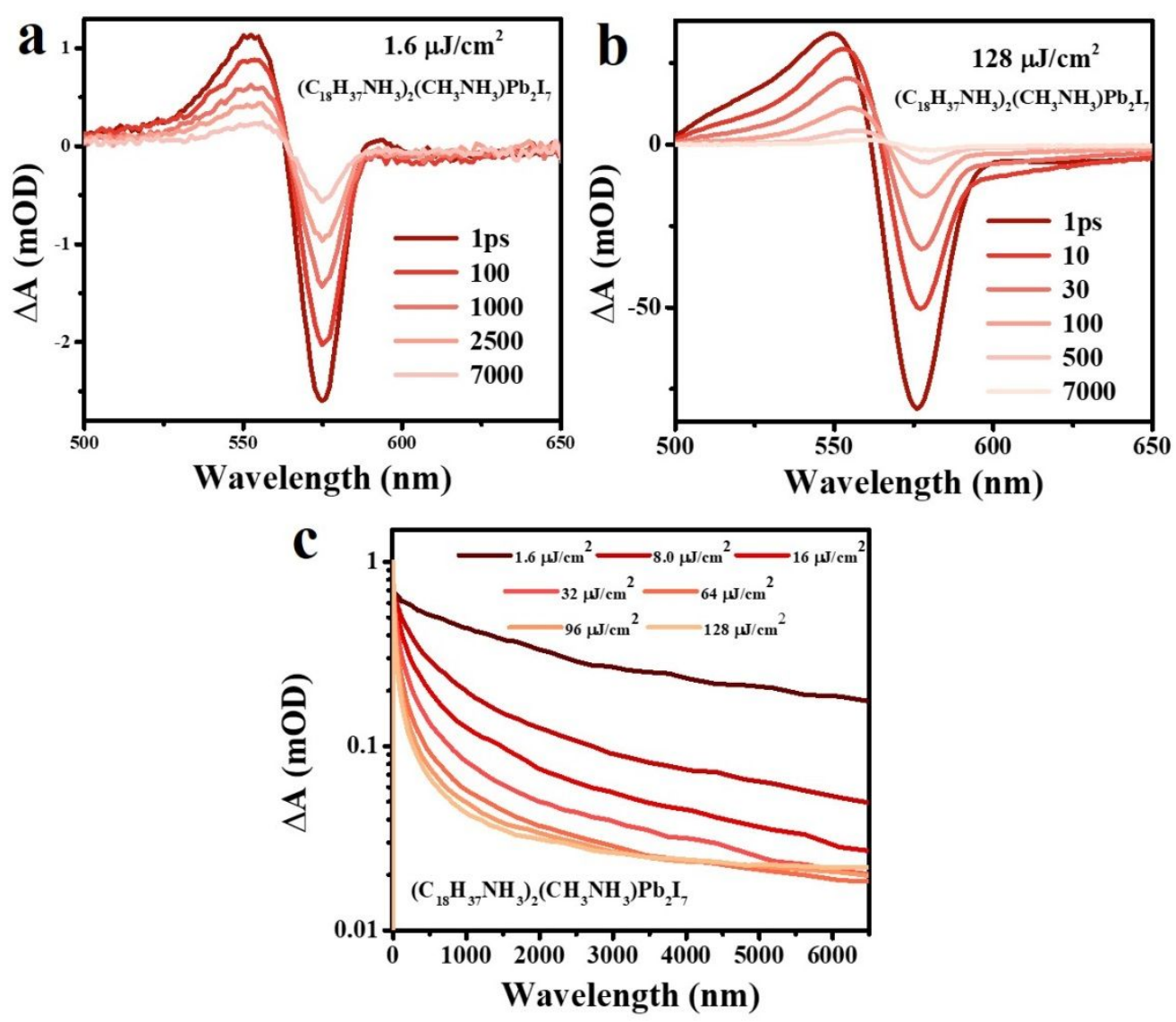

Figure S7. (a, b) TA spectra of $\left(\mathrm{C}_{18} \mathrm{H}_{37} \mathrm{NH}_{3}\right)_{2}\left(\mathrm{CH}_{3} \mathrm{NH}_{3}\right) \mathrm{Pb}_{2} \mathrm{I}_{7}$ perovskites (larger QW thickness) at indicated delay times under $400 \mathrm{~nm}$ excitation with excitation intensity of $1.6 \mu \mathrm{J} / \mathrm{cm}^{2}$ and $128 \mu \mathrm{J} / \mathrm{cm}^{2}$. (c) $\mathrm{XB}$ kinetics of $\left(\mathrm{C}_{18} \mathrm{H}_{37} \mathrm{NH}_{3}\right)_{2}\left(\mathrm{CH}_{3} \mathrm{NH}_{3}\right) \mathrm{Pb}_{2} \mathrm{I}_{7} \mathrm{SCs}$ probed at $580 \mathrm{~nm}$ under different excitation intensities. The result shows that no derivative-like TA signal is observed in 2D perovskites with a larger QW thickness. 

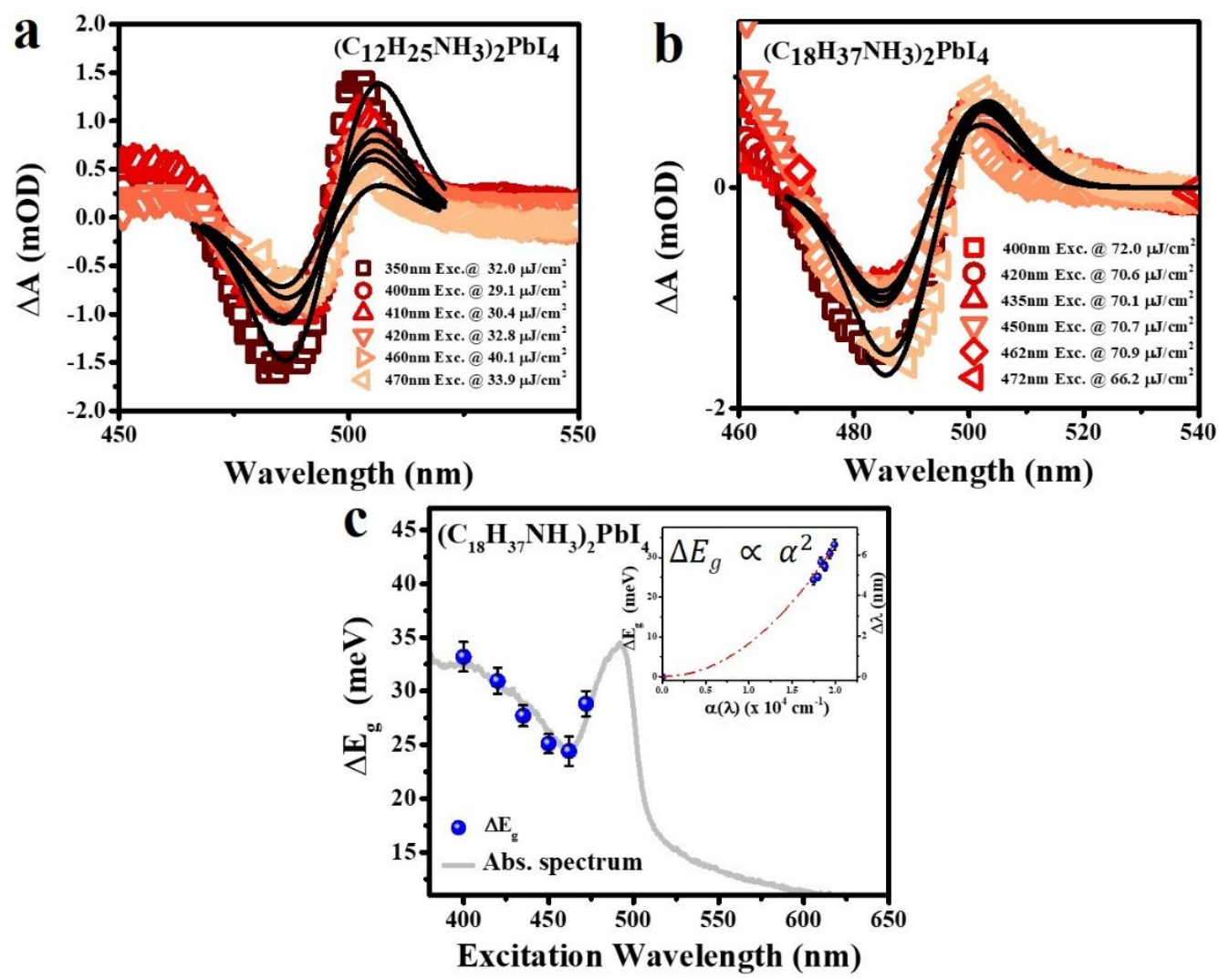

Figure S8. Derivative-like TA spectra of (a) $\left(\mathrm{C}_{12} \mathrm{H}_{25} \mathrm{NH}_{3}\right)_{2} \mathrm{PbI}_{4}$ and (b) $\left(\mathrm{C}_{18} \mathrm{H}_{37} \mathrm{NH}_{3}\right)_{2} \mathrm{PbI}_{4}$ perovskites collected at different excitation wavelengths at a delay time of 3 ns. The black solid lines are the fits of the TA spectra for the determination of $\Delta E_{g}$; the fitting parameters are listed in Table $\mathrm{S} 2$ for $\mathrm{m}=12$ and Table $\mathrm{S} 3$ for $\mathrm{m}=18$ perovskites. (c) $\Delta E_{g}$ at various excitation wavelengths for $\mathrm{m}=182 \mathrm{D}$ perovskites, showing a distribution well consistent with the absorption spectrum. The inset is the plot of $\Delta E_{g}$ as a function of absorption coefficient $(\alpha(\lambda))$, showing a quadratic dependence of $\Delta E_{g}$ on $\alpha(\lambda)$. 

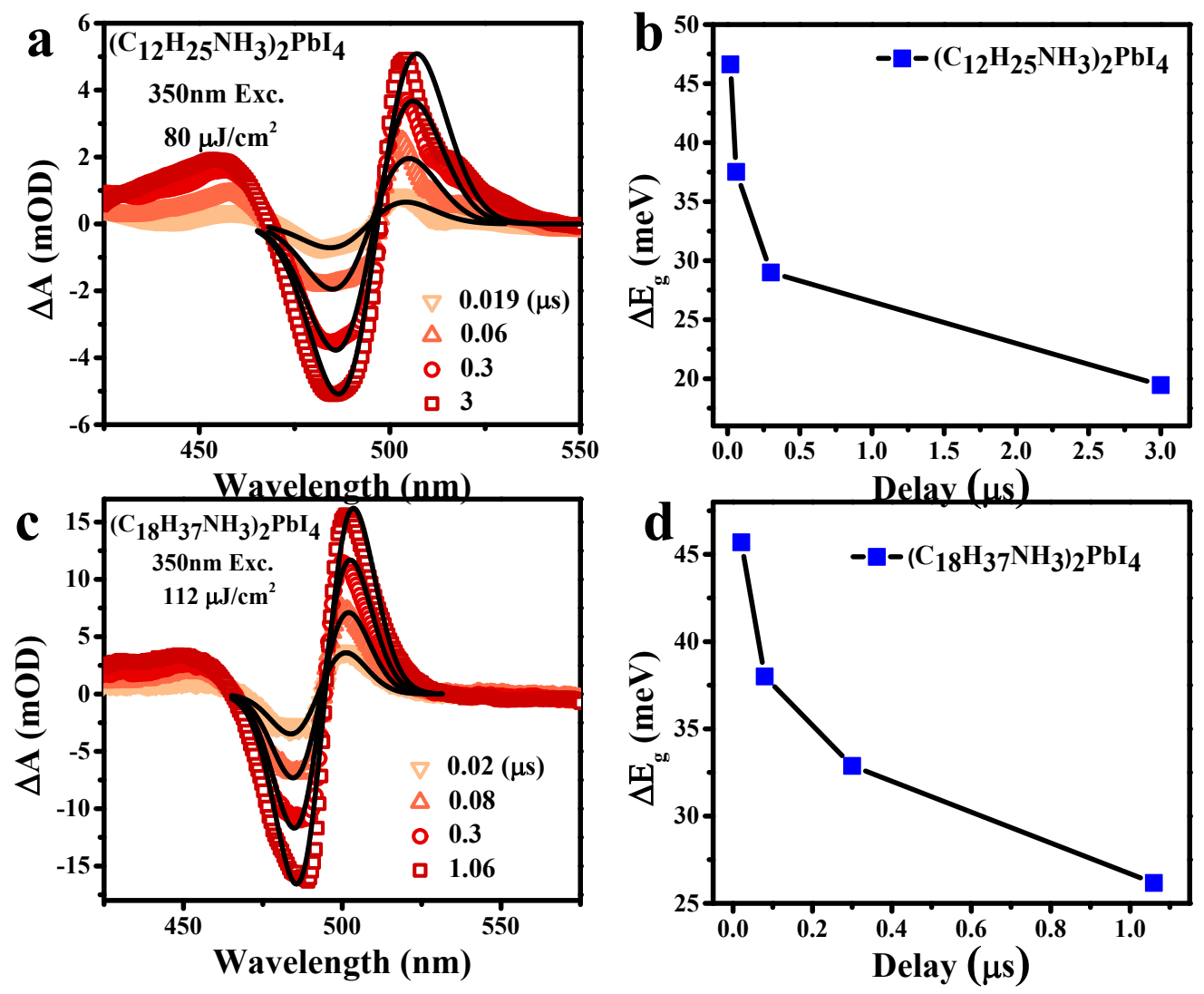

Figure S9. (a, c) TA spectra of (a) $\left(\mathrm{C}_{12} \mathrm{H}_{25} \mathrm{NH}_{3}\right)_{2} \mathrm{PbI}_{4}$ and (b) $\left(\mathrm{C}_{18} \mathrm{H}_{37} \mathrm{NH}_{3}\right)_{2} \mathrm{PbI}_{4} 2 \mathrm{D}$ perovskites collected on ns to $\mu$ s time scale. The black solid lines are the fits of TA spectra to determine the $\Delta E_{g}$ at different delay times. The fitting parameters are listed in Table S4 and S5. (b, d) Plots of $\Delta E_{g}$ as a function of delay time for (b) $\left(\mathrm{C}_{12} \mathrm{H}_{25} \mathrm{NH}_{3}\right)_{2} \mathrm{PbI}_{4}$ and (d) $\left(\mathrm{C}_{18} \mathrm{H}_{37} \mathrm{NH}_{3}\right)_{2} \mathrm{PbI}_{4} 2 \mathrm{D}$ perovskites. 
Table S1. Fitting parameters for the normalized TA kinetics shown in Figure $3 b$ and S6c. The kinetics are fitted by a multiple-exponential function $\left(\mathrm{y}=\Sigma_{\mathrm{i}} \mathrm{a}_{\mathrm{i}} \exp \left(-\mathrm{t} / \tau_{\mathrm{i}}\right)\right) . \tau_{\text {ave. }}$ is the amplitude weighted average lifetime.

\begin{tabular}{|c|c|c|c|c|c|c|c|}
\hline Sample & $\tau_{1}(\mu s)$ & $a_{1}(\%)$ & $\tau_{2}(\mu s)$ & $\mathbf{a}_{2}(\%)$ & $\tau_{3}(\mu s)$ & $a_{3}(\%)$ & $\tau_{\text {ave. }}(\mu \mathbf{s})$ \\
\hline$\left(\mathrm{C}_{10} \mathrm{H}_{21} \mathrm{NH}_{3}\right)_{2} \mathrm{PbI}{ }_{4}$ & 0.012 & 57.7 & 0.09 & 42.3 & - & - & 0.045 \\
\hline$\left(\mathrm{C}_{12} \mathrm{H}_{25} \mathrm{NH}_{32}\right)_{2} \mathrm{PbI}$ & 0.03 & 55.0 & 0.51 & 30.4 & 9.31 & 14.6 & 1.53 \\
\hline$\left(\mathrm{C}_{18} \mathrm{H}_{37} \mathrm{NH}_{3}\right)_{2} \mathrm{PbI}_{4}$ & 0.078 & 54.8 & 0.87 & 32.7 & 14.6 & 12.5 & 2.15 \\
\hline
\end{tabular}

Table S2. Fitting parameters for the derivative-like TA spectra of $\left(\mathrm{C}_{12} \mathrm{H}_{25} \mathrm{NH}_{3}\right)_{2} \mathrm{PbI}_{4}$ collected at different excitation wavelengths shown in Figure S8a for the determination of $\Delta \mathrm{E}_{\mathrm{g}}$. These TA spectra are fitted by the equation shown in the table, where $\mathrm{C}$ is a constant, a is amplitude, $\Delta \lambda$ is the spectral shift and 492.15 is the wavelength position of the first excitonic absorption peak of the perovskite.

\begin{tabular}{|c|c|c|c|c|}
\hline \multirow{2}{*}{ Equation } & \multicolumn{4}{|c|}{$\mathrm{y}=\mathrm{C}^{*}\left(\exp \left(-((\mathrm{x}-492.15-\Delta \lambda) / 14)^{2}\right)-\mathrm{a} * \exp \left(-((\mathrm{x}-492.15) / 14)^{2}\right)\right)$} \\
\hline Wavelength $(\mathrm{nm})$ & $\mathrm{C}$ & $\mathrm{a}$ & $\Delta \lambda(\mathrm{nm})$ & $\Delta E_{g}(\mathrm{meV})$ \\
\hline 350 & 3.01 & 1.03 & 8.09 & 40.7 \\
\hline 400 & 1.82 & 0.96 & 7.24 & 36.5 \\
\hline 410 & 2.5 & 1.06 & 6.56 & 33.1 \\
\hline 420 & 2.65 & 1.10 & 5.06 & 25.6 \\
\hline 460 & 3.98 & 1.10 & 3.24 & 16.5 \\
\hline 470 & 1.82 & 1.23 & 4.55 & 23.1 \\
\hline
\end{tabular}


Table S3. Fitting parameters for the derivative-like TA spectra of $\left(\mathrm{C}_{18} \mathrm{H}_{37} \mathrm{NH}_{3}\right)_{2} \mathrm{PbI}_{4}$ collected at different excitation wavelengths shown in Figure $\mathrm{S} 8 \mathrm{~b}$ for the determination of $\Delta \mathrm{E}_{\mathrm{g}}$. These TA spectra are fitted by the equation shown in the table, where $\mathrm{C}$ is a constant, $\mathrm{a}$ is amplitude, $\Delta \lambda$ is the spectral shift and 490 is the wavelength position of the first excitonic absorption peak of the perovskite.

\begin{tabular}{|c|c|c|c|c|}
\hline Equation & \multicolumn{4}{|c|}{$y=C *\left(\exp \left(-((\mathrm{x}-490-\Delta \lambda) / 12.1)^{2}\right)-\mathrm{a} * \exp \left(-((\mathrm{x}-490) / 12.1)^{2}\right)\right)$} \\
\hline Wavelength $(\mathrm{nm})$ & $\mathrm{C}$ & $\mathrm{a}$ & $\Delta \lambda(\mathrm{nm})$ & $\Delta E_{g}(\mathrm{meV})$ \\
\hline 400 & 2.16 & 1.31 & 6.51 & 33.2 \\
\hline 420 & 2.00 & 1.10 & 6.06 & 30.9 \\
\hline 435 & 2.20 & 1.11 & 5.42 & 27.7 \\
\hline 450 & 2.42 & 1.13 & 4.91 & 25.1 \\
\hline 462 & 2.09 & 1.15 & 4.77 & 24.4 \\
\hline 472 & 2.72 & 1.28 & 5.64 & 28.8 \\
\hline
\end{tabular}

Table S4. Fitting parameters for TA spectra of $\left(\mathrm{C}_{12} \mathrm{H}_{25} \mathrm{NH}_{3}\right)_{2} \mathrm{PbI}_{4}$ shown in Figure S9a These TA spectra for the determination of $\Delta \mathrm{E}_{\mathrm{g}}$. These TA spectra are fitted by the equation shown in the table, where $\mathrm{C}$ is a constant, a is amplitude, $\Delta \lambda$ is the spectral shift and 492.15 is the wavelength position of the first excitonic absorption peak of the perovskite.

\begin{tabular}{|c|c|c|c|c|}
\hline Equation & \multicolumn{4}{|c|}{$y=C *\left(\exp \left(-((x-492.15-\Delta \lambda) / 14)^{2}\right)-\mathrm{a}^{*} \exp \left(-((\mathrm{x}-492.15) / 14)^{2}\right)\right)$} \\
\hline Delay $(\mu \mathrm{s})$ & $\mathrm{C}$ & $\mathrm{a}$ & $\Delta \lambda(\mathrm{nm})$ & $\Delta E_{g}(\mathrm{meV})$ \\
\hline 0.019 & 9.62 & 1.00 & 9.28 & 46.6 \\
\hline 0.06 & 8.52 & 1.01 & 7.44 & 37.5 \\
\hline 0.3 & 5.72 & 1.00 & 5.73 & 29.0 \\
\hline 3 & 2.92 & 1.02 & 3.83 & 19.4 \\
\hline
\end{tabular}


Table S5. Fitting parameters for nanosecond TA spectra of $\left(\mathrm{C}_{18} \mathrm{H}_{37} \mathrm{NH}_{3}\right)_{2} \mathrm{PbI}_{4}$ shown in Figure S9c for the determination of $\Delta \mathrm{E}_{\mathrm{g}}$. These TA spectra are fitted by the equation shown in the table, where $\mathrm{C}$ is a constant, a is amplitude, $\Delta \lambda$ is the spectral shift and 490 is the wavelength position of the first excitonic absorption peak of the perovskite.

\begin{tabular}{|c|c|c|c|c|}
\hline Equation & \multicolumn{4}{|c|}{$\mathrm{y}=\mathrm{C}^{*}\left(\exp \left(-((\mathrm{x}-490-\Delta \lambda) / 12.1)^{2}\right)-\mathrm{a}^{*} \exp \left(-((\mathrm{x}-490) / 12.1)^{2}\right)\right)$} \\
\hline Delay $(\mu \mathrm{s})$ & $\mathrm{C}$ & $\mathrm{a}$ & $\Delta \lambda(\mathrm{nm})$ & $\Delta E_{g}(\mathrm{meV})$ \\
\hline 0.02 & 27.94 & 1.01 & 9.01 & 45.7 \\
\hline 0.08 & 23.49 & 1.01 & 7.47 & 38.0 \\
\hline 0.3 & 16.45 & 1.00 & 6.45 & 32.9 \\
\hline 1.06 & 10.12 & 0.99 & 5.12 & 26.2 \\
\hline
\end{tabular}

\section{Supplementary Note 1 :}

\section{Simulations of Auger-assisted inter-QW electron transfer and the distributions}

\section{of separated electrons and holes in $2 \mathrm{D}$ layered perovskites.}

The laser excitation is normal to the QW plane and the number of QW layer along the thickness direction is labeled as $i=1,2,3 \ldots$ According to the Beer's law, the absorbed photon number (the number of excitons) in the $i^{\text {th }} \mathrm{QW}$ layer $n_{i}$ can be described by

$$
n_{i}=N_{0} e^{-(i-1) \alpha d} \alpha d=n_{1} e^{-(i-1) \alpha d}
$$

where $\alpha$ is the absorption coefficient of $2 \mathrm{D}$ perovskites, $\mathrm{d}$ is the interlayer spacing and $n_{1}$ is the absorbed photon number (equals to the number of exciton) in the first layer (i.e., $n_{l}=N_{0} \alpha d$ ). For simplicity, the probability (number of transferred electrons in relative to the total exciton density in a $\mathrm{QW}$ ) of electron transfer to the ligand LUMO via Auger process is denoted as $\chi ; \chi$ is assumed to be a constant for all QW layers. In 
a QW, the probabilities of Auger-assisted electron transfer (AET) to the LUMO of the two neighboring ligand layers are the same, and the electron at the ligand LUMO level can also transfer back the original QW (see Figure 4 in the main text), the probability of electron transfer to the adjacent QW should be $\chi / 4$. Then the net number of separated electrons $\left(\Delta n_{1}\right)$ generated by Auger-assisted electron transfer (AET) in the first QW layer can be derived as

$$
\begin{aligned}
\Delta n_{1} & =-\frac{1}{4} \chi n_{1}+\frac{1}{4} \chi n_{2}=\frac{\chi}{4}\left(-N_{0} \alpha d+N_{0} e^{-\alpha d} \alpha d\right) \\
& =-\frac{\chi}{4} N_{0} \alpha d\left(1-e^{-\alpha d}\right) \approx-\frac{\chi}{4} N_{0}(\alpha \mathrm{d})^{2}
\end{aligned}
$$

where the first and second terms represent the outflow and inflow numbers of the electrons, respectively. The negative sign in the final expression of Eq.(S2) indicates that the first QW layer has a net electron outflow (net holes left in the first QW).

Next, we can also estimate the changed number of electrons $\left(\Delta n_{2}\right)$ induced by AET in the second QW layer as

$$
\begin{aligned}
\Delta n_{2} & =\left(\frac{\chi}{4} n_{1}-\frac{\chi}{4} n_{2}\right)-\left(\frac{\chi}{4} n_{2}-\frac{\chi}{4} n_{3}\right)=\frac{\chi}{4}\left(n_{1}+n_{3}-2 n_{2}\right) \\
& =\frac{\chi}{4} N_{0} \alpha d\left(1+e^{-2 \alpha d}-2 e^{-\alpha d}\right) \\
& =\frac{\chi}{4} N_{0} \alpha \mathrm{d}\left(1-e^{-\alpha d}\right)^{2} \approx \frac{\chi}{4} N_{0}(\alpha \mathrm{d})^{3}
\end{aligned}
$$

The positive sign in final expression of Eq.(S3) indicates that the second QW layer has a net electron inflow.

Similarly, the net number of electrons $\left(\Delta n_{i}\right)$ induced in the $i^{\text {th }} \mathrm{QW}$ layer (for $i \geq 2$ ) can be directly derived as

$$
\begin{aligned}
\Delta n_{i} & =\left(\frac{\chi}{4} n_{i-1}-\frac{\chi}{4} n_{i}\right)-\left(\frac{\chi}{4} n_{i}-\frac{\chi}{4} n_{i+1}\right)=\frac{\chi}{4}\left(n_{i-1}+n_{i+1}-2 n_{i}\right) \\
& =\frac{\chi}{4} N_{0} \alpha d\left(e^{-(i-2) \alpha d}+e^{-i \alpha d}-2 e^{-(i-1) \alpha d}\right) \\
& =\frac{\chi}{4} N_{0} \alpha \mathrm{d} e^{-(i-2) \alpha d}\left(1-e^{-\alpha d}\right)^{2} \\
& \approx \frac{\chi}{4} N_{0}(\alpha \mathrm{d})^{3} e^{-(i-2) \alpha d}
\end{aligned}
$$

Eq.(S4) indicates that the QW layers with $i \geq 2$ all have a net electron inflow, and the 
number of net electrons $\left(\Delta n_{i}\right)$ deceases as $i$ increases. We therefore can simulate the distribution of the separated electrons and holes as shown in Figure S10, showing that the separated holes are only in the first QW layer and separated electrons distribute starting from $i=2 \mathrm{QW}$ layers.
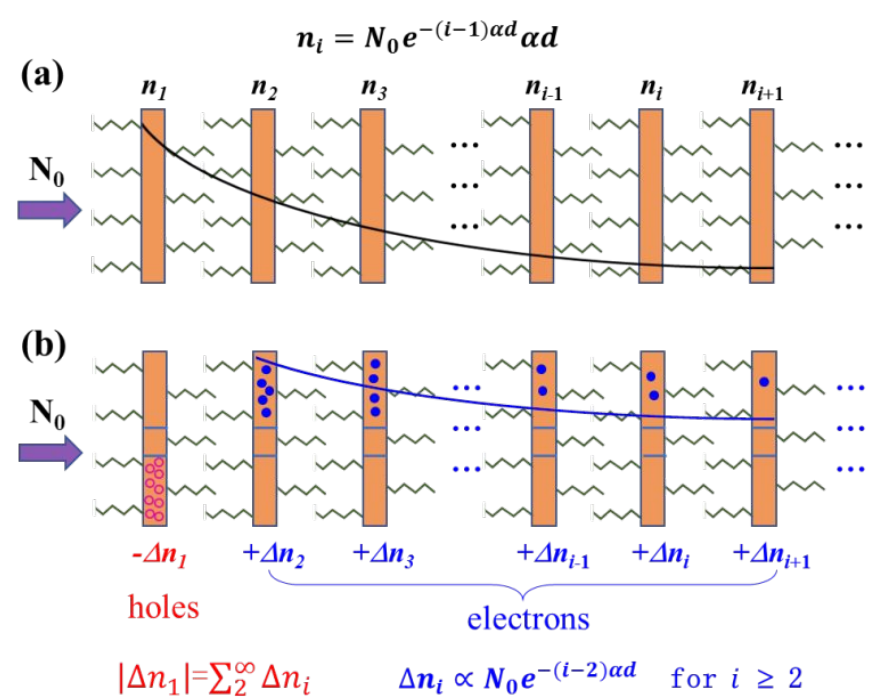

Figure S10. (a) The distribution of the absorbed photons (the number of photogenerated excitons) in the QW layers along the thickness direction. $\mathrm{N}_{0}$ represents the total incident photon number. (b) The distribution of separated electrons and holes in the layered 2D perovskites, showing that the separated holes are only in the first QW layer and separated electrons distribute starting from $i=2 \mathrm{QW}$ layers.

The intensity of the internal electric filed $\left(E_{i n}\right)$ induced by the separated electrons and holes should be proportional to the number of separated charges as

$$
E_{\text {in }} \propto \frac{\chi}{4} N_{0}(\alpha \mathrm{d})^{2}=\frac{\chi}{4} n_{1} \alpha \mathrm{d}
$$

According to the quantum confined Stark effect (QCSE) theory, the change of QW band gap energy $\left(\Delta E_{g}\right)$ should follow $\Delta E_{g}=-\beta E_{i n}{ }^{2}$, which can thus be described as

$$
\Delta E_{g} \propto\left(E_{i n}\right)^{2} \propto\left(\chi n_{1} \alpha \mathrm{d}\right)^{2}
$$

Therefore, if the number of absorbed photons in the first layer $\left(n_{1}=N_{0} \alpha d\right)$ and $\chi$ are unchanged, $\Delta E_{g}$ should exhibit a quadratic dependence on $\alpha$, which is confirmed by 
our experimental results (see Figure 5 and Figure S8). 